\title{
Prospects for population genetic studies of cosmopolitan freshwater sponges of the Spongillidae family in Lake Baikal
}

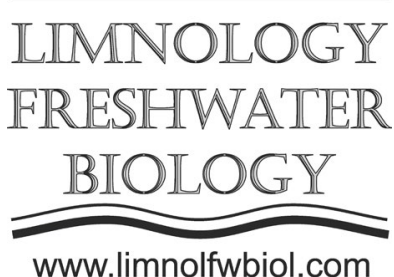

\author{
Yakhnenko A.S. ${ }^{1,2 \star \oplus}$, Itskovich V.B. ${ }^{1 \oplus}$ \\ ${ }^{1}$ Limnological Institute, Siberian Branch of the Russian Academy of Sciences, 3, Ulan-Batorskaya, Irkutsk, Russia, 664033 \\ ${ }^{2}$ International Intergovernmental Organization Joint Institute for Nuclear Research, 6 Joliot-Curie St, Dubna, Moscow Region, Russia, \\ 141980
}

\begin{abstract}
Cosmopolitan freshwater sponges inhabit Lake Baikal. They are of great interest for carrying out population genetic studies. Microsatellite markers are best suited for population genetic studies of sponges. To date, no markers have been developed for the species Ephydatia muelleri that is widespread in Lake Baikal and found across the northern hemisphere. In the course of this study, a search was carried out for microsatellite markers in the previously published complete genome of E.muelleri. The most promising microsatellite loci were selected among those found in the genome data. Selected loci were tested on E.muelleri DNA samples. A set of 11 specific variable microsatellite markers was developed and tested for further population genetic studies of E.muelleri. Also, the Maloye More Strait area of Lake Baikal was surveyed to determine the sites of mass accumulation of the Spongilliadae family representatives. An analysis of the species composition of cosmopolitan sponges was carried out for Site 1 (Olkhon Island). Two species were identified: E.muelleri (72\%) and Spongilla lacusris (18\%).
\end{abstract}

Keywords: Genetic markers, microsatellites, population genetics, sponges, Porifera, Lake Baikal

\section{Introduction}

Sponges are one of the oldest multicellular organisms that have survived and thrive today (Philippe et al., 2009). More than 8500 sponge species were described and accepted worldwide (van Soest et al., 2012). Sponges lead an attached lifestyle and have a filtration type of nutrition (van Soest et al., 2012). Most freshwater sponge species are capable of asexual reproduction (Maldonado and Riesgo, 2008) and can survive under unfavorable conditions, for example, desiccation (Manconi and Pronzato, 2008), in the form of resting stages, gemmules. Due to the limited swimming ability of the larvae, most sponge species are found only in a limited habitat or are endemic. However, there are cosmopolitan sponge genera that spread through gemmules (Bilton et al., 2001; Manconi and Pronzato, 2008). Sponges make a significant contribution to the ecology of both marine and freshwater ecosystems (Dröscher and Waringer, 2007; Bell, 2008; Vohmann et al., 2009). Due to the filtration type of nutrition, sponges serve as sensitive bioindicators of the pollution of aquatic ecosystems (Roveta et al., 2021).

Several studies of the population structure were conducted for marine sponges (Duran et al., 2004;

*Corresponding author.

E-mail address: yakhnenkoas@gmail.com (Yakhnenko A.S.)

Received: December 14, 2021; Accepted: December 26, 2021; Available online: February 15, 2022
Calderón et al., 2007; Hoshino et al., 2008; Blanquer et al., 2009; Blanquer and Uriz, 2010; 2011; Dailianis et al., 2011; Guardiola et al., 2012; Noyer and Becerro, 2012; Riesgo et al., 2016); however, data for freshwater sponges are very scarce.

For the freshwater sponge, Ephydatia fluviatilis, an analysis for compliance with the hypothesis of monopolization, which is confirmed for crustaceans (De Gelas and De Meester, 2005; Muñoz and Pacios, 2010), bryozoans (Hoare et al., 2001; Massard and Geimer, 2008) and rotifers (Mills et al., 2007; Fontaneto et al., 2008) was carried out. For samples from Central Italy located within $100 \mathrm{~km}$, no genetic differentiation was found. Differentiation was found between populations from Italy and Hungary, located more than $600 \mathrm{~km}$ apart. Sponges in terms of their genetic relationships between populations are similar to rotifers and crustaceans and can be used in combination with these organisms for further studies of the monopolization hypothesis (Lucentini et al., 2013). Additionally, the population structure of sponges inhabiting the River-Sieg system was studied for the E.fluviatilis freshwater sponge. That study revealed a clear genetic differentiation between populations living at a distance of up to 50 kilometers (Li et al., 2018). The population structure of freshwater sponges has not previously been studied for large

(C) Author(s) 2021. This work is distributed under the Creative Commons AttributionNonCommercial 4.0 International License. 
ancient lakes. However, the relevance of such studies is undoubtable because, for example, Lake Baikal is a unique ecosystem that has existed for millions of years (Kozhov, 1962; Jaguś et al., 2015), and is mainly represented by endemic flora and fauna.

Cosmopolitan sponges live only in shallow waters; therefore, their settlement and distribution pattern in Lake Baikal is not obvious. According to paleontological data, sponges have lived in Baikal for at least $10 \mathrm{Ma}$ (Veynberg, 2009). Since the formation of Lake Baikal, catastrophic events have occurred several times, causing a dramatic change in the level of the lake (Arzhannikov et al., 2017; 2021). There is no evidence that the episodes of the water levels changes led to the disappearance and subsequent recolonization by cosmopolitan sponge species of Lake Baikal or they developed continuously in the water area of the lake. The level of migration of cosmopolitan sponges between the bays separated from the main water area of Lake Baikal is also not obvious. The search for the answers to these questions is of interest and requires the study of the population genetic structure of Baikal cosmopolitan sponges. Also, endemic sponges inhabit Lake Baikal. Baikal endemic sponges have a common ancestor with the cosmopolitan genus Ephydatia (Itskovich et al., 2008). During the formation of an endemic family, Baikal endemic sponges lost their ability to form gemmules and acquired a long-term life cycle. The question remains open of how such changes affected the ability of endemic sponges to settle and migrate within Lake Baikal. It is necessary to carry out a comparative analysis between the population structures of the cosmopolitan sponges of the genus Ephydatia inhabiting Lake Baikal and the endemic ones.

According to the data from the recent revision of Baikal sponges (Efremova, 2004), there are members of four genera of the cosmopolitan family Spongillidae: Ephydatia Lamouroux, 1816, including the species Ephydatia muelleri, Spongilla Lamarck, 1816, Eunapius Gray, 1867, and Trochospongilla Vejdovsky, 1888. We found massive concentrations of individuals of this species in the Maloye More Strait. Therefore, this species was chosen as a promising one for carrying out population genetic studies of cosmopolitan freshwater sponges in Lake Baikal.

Molecular genetic markers were used for carrying out population genetic studies of sponges. The low resolution of mitochondrial markers such as COI was indicated for sponges (Yakhnenko and Itskovich, 2020a); however, microsatellite markers were used quite successfully. Several sets of microsatellite markers were published for marine sponge species (Duran et al., 2002; Knowlton et al., 2003; Blanquer et al., 2005; Hoshino and Fujita, 2006; Noyer et al., 2009; Anderson et al., 2010; Dailianis and Tsigenopoulos, 2010; Guardiola et al., 2012; Giles et al., 2013; Taboada et al., 2018). For freshwater sponges, microsatellite markers were developed only for E.fluviatilis (Anderson et al., 2010). As we have shown previously (Yakhnenko and Itskovich, 2020b), these markers are not suitable for population genetic studies of other species of the Spongillidae family, specifically for E.muelleri, although these species are closely related. Thus, it is necessary to develop and test a set of microsatellite markers specific for E.muelleri. To solve this problem, an analysis of the chromosomal level genomic data of E.muelleri published previously (Kenny et al., 2020) will be carried out.

To assess the prospects for analyzing the genetic distances between the populations of cosmopolitan freshwater sponges in Lake Baikal, it is also necessary to conduct fieldwork to survey the coves and bays of the Maloye More Strait at Lake Baikal to select the site of mass accumulation of the Spongillidae members.

\section{Materials and methods}

\subsection{Sampling}

Sponges were collected in November 2019, July and November 2020 in four bays and lagoons in the area of the Maloye More Strait at Lake Baikal (Fig. 1; Fig. 2; Table 1) at depths of 0 to 1.5 meters. Most of the sponge samples were collected from the back surface of the stones.

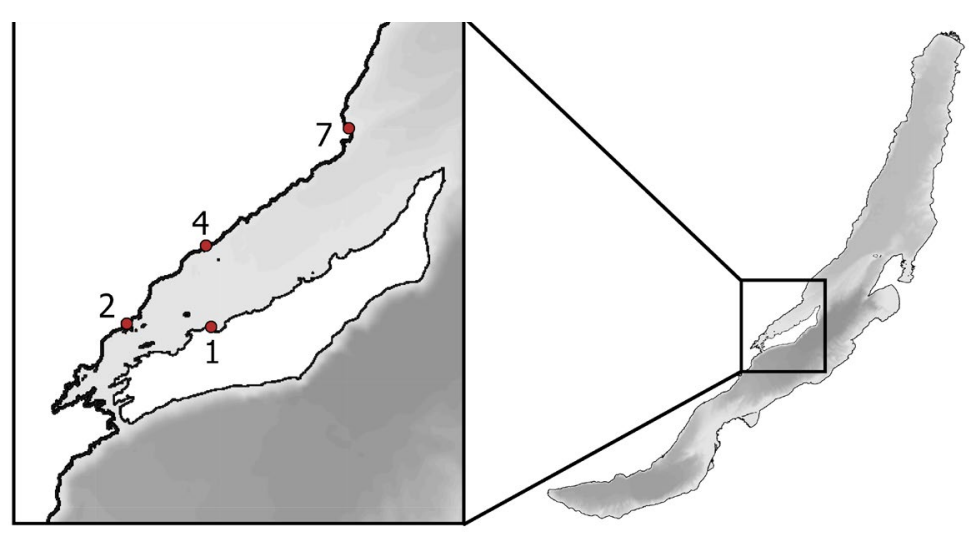

Fig.1. Spongillidae mass accumulation sites near the Maloye More Strait.

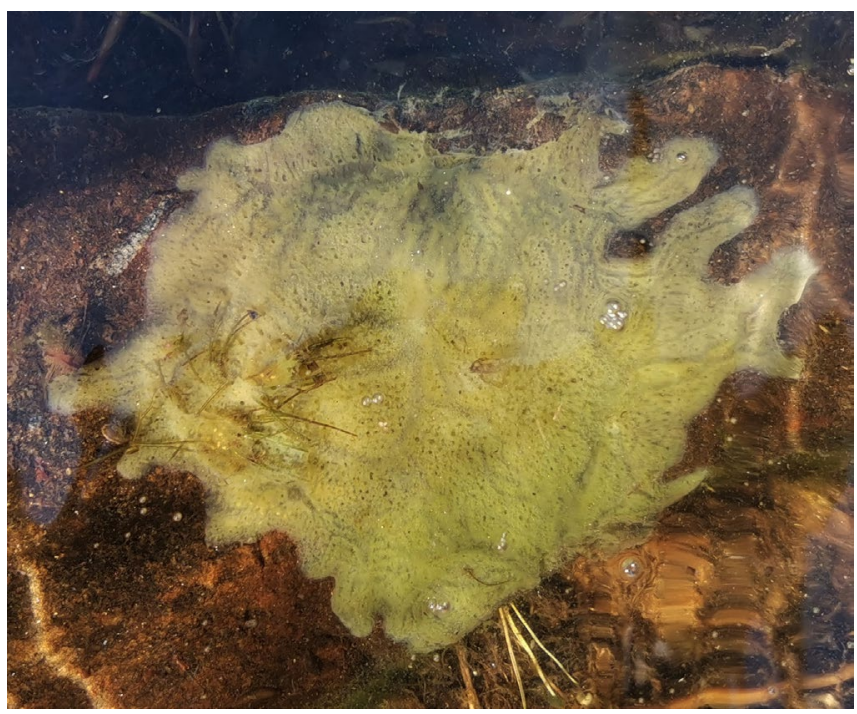

Fig.2. Sponge sample of the genus Ephydatia from Site 1. 
The samples were fixed in $70 \%$ ethanol immediately after collection. After 24 hours ethanol was replaced with a new one for long-term storage at $+4 \mathrm{C}^{\circ}$. Some samples in the form of gemmules were washed from the remains of the skeleton and were placed in a refrigerator at $+4 \mathrm{C}^{\circ}$ in a humid state without access to sunlight.

Species were identified based on morphological characteristics such as appearance, length and shape of spicules and gemmosclera using a light microscope. Spicules were isolated from a small fragment of the sample. The organic part was dissolved by decolorant; then, the decolorant was washed off with distilled water.

\subsection{Microsatellite markers development}

Tandem repeats with 7 to 30 blocks in the complete genome data on E.muelleri (Kenny et al., 2020) were searched for using the STR detection tool in Galaxy software (Fungtammasan et al., 2015). The most suitable microsatellites with flanking regions were selected among the identified ones. For the set of 28 microsatellites, primer pairs were designed and tested. Primers were searched for using Primer-BLAST NCBI (Ye et al., 2012). Primers were purchased from Evrogen (Moscow, Russia) and Syntol (Moscow, Russia).

\subsection{Microsatellite amplification and genotyping}

DNA from sponge samples was isolated using the CTAB method (Gustincich et al., 1991). PCR was performed in a Peltier Thermal Cycler (MJ Research, USA) using a ScreenMix-HS kit (Evrogen), Russia. The PCR program was optimized. Initial denaturation carried out for $2 \mathrm{~min}$ at $94 \mathrm{C}^{\circ}$ followed by 11 cycles of denaturation for $30 \mathrm{sec}$ at $94 \mathrm{C}^{\circ}$, annealing for 30 sec at $65-55 \mathrm{C}^{\circ}$ (one-degree reduction every cycle), the extension for $30 \mathrm{sec}$ at $72 \mathrm{C}^{\circ}$ followed by 24 cycles of
Table 1. Coordinates of sampling sites

\begin{tabular}{|c|c|}
\hline Sampling site No & Coordinates \\
\hline 1 & $53^{\circ} 09^{\prime} 10.4 » \mathrm{~N} 107^{\circ} 10^{\prime} 11.4 » \mathrm{E}$ \\
\hline 2 & $53^{\circ} 09^{\prime} 32.5 » \mathrm{~N} 106^{\circ} 56^{\prime} 56.9 » \mathrm{E}$ \\
\hline 4 & $53^{\circ} 16^{\prime} 59.1 » \mathrm{~N} 107^{\circ} 09^{\prime} 21.4 » \mathrm{E}$ \\
\hline 7 & $53^{\circ} 28^{\prime} 11.1 » \mathrm{~N} 107^{\circ} 32^{\prime} 02.5 » \mathrm{E}$ \\
\hline
\end{tabular}

denaturation for $30 \mathrm{sec}$ at $94 \mathrm{C}^{\circ}$, annealing for $30 \mathrm{sec}$ at $55 \mathrm{C}^{\circ}$, the extension for $30 \mathrm{sec}$ at $72 \mathrm{C}^{\circ}$, and then the final extension for $8 \mathrm{~min}$ at $72 \mathrm{C}^{\circ}$.

PCR products were visualized in a $2 \%$ agarose gel with Syber Green dye. The exact size of PCR products was estimated using fragment analysis on an ABI 3130xl Genetic Analyzer (Syntol, Moscow) and analyzed with the GenMarker 3.01 software.

\section{Results and discussion}

During the fieldwork, seven bays and lagoons were surveyed in the area of the Maloye More Strait at Lake Baikal. Mass accumulations of freshwater cosmopolitan sponges were found at four out of seven locations (Fig. 1).

We analyzed species composition for Site 1 . The collections contained samples of two species: Spongilla lacustris (18\%) and Ephydatia muelleri (72\%).

Based on the analysis of the E.muelleri genomic data, we selected 28 promising microsatellite loci with flanking regions suitable for the development of primers. A pair of primers for each locus was developed. Each locus was tested on four DNA samples of E.muelleri. Fragment analysis was carried out for 17 loci, giving clear bands in the gel electrophoresis. Among the analyzed loci, 11 were variable, which were included in the set of microsatellite markers (Table 2). For fragment analysis, fluorescent labels were attached to the forward primers. (Table 3).

Table 2. Coordinates of microsatellite markers in genomic data on E.muelleri (Kenny et al., 2020)

\begin{tabular}{|l|c|c|c|c|c|c|}
\hline Locus Name & Scaffold No* & Query start* & Query end* & $\begin{array}{c}\text { Sequence } \\
\text { length }\end{array}$ & Repeat type & $\begin{array}{c}\text { n of } \\
\text { alleles }\end{array}$ \\
\hline Emu_241 & scaffold_0019 & 1357021 & 1357338 & 318 & (CT)14 & 4 \\
Emu_249 & scaffold_0019 & 1810514 & 1810717 & 204 & (CA)13 & 2 \\
Emu_257 & scaffold_0019 & 1386901 & 1387195 & 295 & (CG)6(CA)21 & 2 \\
Emu_187 & scaffold_0016 & 868299 & 867998 & 302 & (CA)18 & 2 \\
Emu_291 & scaffold_0020 & 6431917 & 6432205 & 289 & (TG)9 & 3 \\
Emu_124 & scaffold_0012 & 8003328 & 8003132 & 197 & (GTG)5 & 2 \\
Emu_369 & scaffold_0023 & 541061 & 540749 & 313 & (GT)27 & 3 \\
Emu_266 & scaffold_0019 & 6087901 & 6087619 & 283 & (TGG)7 & 3 \\
Emu_260 & scaffold_0019 & 1043658 & 1043935 & 278 & (CA)28 & 2 \\
Emu_217 & scaffold_0018 & 7273471 & 7273864 & 394 & (AC)9 & 3 \\
Emu_367 & scaffold_0023 & 2188522 & 2188841 & 320 & (AC)23 & 2 \\
\hline
\end{tabular}

*In genome assembly from (Kenny et al., 2020) 
Table 3. Primer pairs for the set of microsatellite markers

\begin{tabular}{|c|c|c|c|c|}
\hline Locus Name & Fw. primer & Rev. Primer & $\begin{array}{c}\text { Tm } \\
\text { Fluorescent } \\
\text { label }\end{array}$ \\
\hline Emu_241 & GCTCACTACTCCAACCCGAC & CAAAGCATGGCGTGTTGTGT & $59-61$ & Tamra \\
Emu_249 & CATCTCTGGTGAAGTACACAGGTG & CAGAGTGCTCCAGCTGCT & $59-61$ & Fam \\
Emu_257 & GAGTCCGTCCTCCTGTTCAC & TGCCAGCAGAGGATATAGCATTC & $59-61$ & R6G \\
Emu_187 & AGCACAGCATAGCAACGATTG & ATGTGGACTTCAGGCACCTG & $59-61$ & Fam \\
Emu_291 & ACGTACCTCAAACACCGTAGTAC & CCCGGCTGTCTGTAAGTCAT & $59-61$ & Tamra \\
Emu_124 & ACTGCCACTCAGGCTCAAG & TTATCCTCAGCGAGAACGTAGTC & $59-61$ & Rox \\
Emu_369 & ACAAGGGTTAGTTAGGAGGCAG & GAGTACTAGGAGGATGAACCAGTG & $59-61$ & Rox \\
Emu_266 & GCCTGTGGTGTAAACAGTGG & CCAAGCGTCCCAGCTAAGAG & $59-61$ & Fam \\
Emu_260 & CCTTCGTCCACAATGGCTTG & ACCTTGGACCAGATTACTCCAAC & $59-61$ & Fam \\
Emu_217 & GTGTCATGGAAGACCAATGAGC & CCTTCAGGCAGGACATCAATACT & $59-61$ & Fam \\
Emu_367 & CCACTGTTCCTTGCCAGACA & CCAGAGGGTGTCAGGATTGAG & $59-61$ & Rox \\
\hline
\end{tabular}

As shown by González-Ramos et al. (2015), a set of nine microsatellite markers is sufficient to conduct a population genetic study of sponges. It was also revealed that with 12 loci or more, the analysis resolution does not change. Blanquer and Uriz (2010) showed the presence of genetic structure within and between populations of marine sponges as well as between different geographic areas using seven microsatellite markers. Duran et al. (2004) identified the genetic structure between geographically distant locations for the Crambe Crambe marine sponge using six microsatellite loci. Both population genetic studies of freshwater sponges used the same set of 11 microsatellite markers (Lucentini et al., 2013; Li et al., 2018).

Thus, the most appropriate number of microsatellite loci for sponges can be from 9 to 12 , taking into account that with a smaller number of microsatellite markers, it is also possible to reveal the population genetic structure, albeit with a lower resolution. Our set of microsatellite markers includes 11 loci and meets all the requirements for high-quality population genetic analysis.

\section{Conclusions}

Based on the results of the fieldwork, the sites of mass accumulations of Spongillidae representatives were identified. We analyzed species diversity for Site 1. The species E.muelleri was the predominant species. A set of 11 specific and variable microsatellite markers was successfully developed and tested for the E.muelleri. Thus, we prepared a basis for population genetic studies of cosmopolitan freshwater sponges in Lake Baikal and further possible studies of the population structure of E.muelleri around the world.

\section{Acknowledgements}

The authors thank Mikhail Yakhnenko, Sergey Arzhannikov, Anastasia Arzhannikova, Ksenia Danilova, Danil Kazakov, Pavel Kosarev, Ksenia Derevtsova, and Vladimir Vasiliev for assistance in fieldwork and sampling.

This study was funded by RFBR and the Government of the Irkutsk Region, project number 20-44-383010 as well as by the State Project number 0279-2021-0011

\section{Conflict of interests}

The authors declare no conflict of interests.

\section{References}

Anderson C.M., Aparicio G.J., Atangana A.R. et al. 2010. Permanent genetic resources added to molecular ecology resources database 1 December 2009-31 January 2010. Molecular Ecology Resources 10(3): 576-579. DOI: 10.1111/j.1755-0998.2010.02851.X

Arzhannikov S.G., Ivanov A., Arzhannikova A. et al. 2017. Catastrophic events in the Quaternary outflow history of Lake Baikal. Earth-Science Reviews 177: 76-113. DOI: 10.1016/j. earscirev.2017.11.011

Arzhannikov S., Arzhannikova A., Ivanov A. et al. 2021. Lake Baikal highstand during MIS 3 recorded by palaeoshorelines on Bolshoi Ushkanii Island. Boreas 50: 101-113. DOI: $10.1111 /$ bor. 12464

Bell J.J. 2008. The functional roles of marine sponges. Estuarine, Coastal and Shelf Science 79(3): 341-353. DOI: 10.1016/j.ecss.2008.05.002

Bilton D.T., Freeland J.R., Okamura B. 2001. Dispersal in freshwater invertebrates. Annual Review of Ecology and Systematics 32: 159-181. DOI: 10.1146/annurev. ecolsys.32.081501.114016

Blanquer A., Uriz M.J. 2010. Population genetics at three spatial scales of a rare sponge living in fragmented habitats. BMC Evolutionary Biology 10(13). DOI: 10.1186/1471-2148-10-13

Blanquer A., Uriz M.J. 2011. Living together apart: the hidden genetic diversity of sponge populations. Molecular Biology and Evolution 28(9). DOI: 10.1093/molbev/msr096

Blanquer A., Uriz M.J., Caujapé-Castells J. 2009. Smallscale spatial genetic structure in Scopalina lophyropoda, an encrusting sponge with philopatric larval dispersal and frequent fission and fusion events. Marine Ecology Progress Series 380: 95-102. DOI: 10.3354/meps07931 
Blanquer A., Uriz M.J., Pascual M. 2005. Polymorphic microsatellite loci isolated from the marine sponge Scopalina lophyropoda (Demospongiae: Halichondrida). Molecular Ecology Notes 5(3). DOI: 10.1111/j.1471-8286.2005.00927.x

Calderón I., Ortega N., Durán S.A. et al. 2007. Finding the relevant scale: clonality and genetic structure in a marine invertebrate (Crambe crambe, Porifera). Molecular Ecology 16(9). DOI: 10.1111/j.1365-294X.2007.03276.X

Dailianis T., Tsigenopoulos C., Dounas C. et al. 2011. Genetic diversity of the imperilled bath sponge Spongia officinalis Linnaeus, 1759 across the Mediterranean Sea: patterns of population differentiation and implications for taxonomy and conservation. Molecular Ecology 20(18): 3757-3772. DOI: 10.1111/j.1365-294X.2011.05222.x

Dailianis T., Tsigenopoulos C.S. 2010. Characterization of polymorphic microsatellite markers for the endangered Mediterranean bath sponge Spongia officinalis L. Conservation Genetics 11(3): 1155-1158. DOI: 10.1007/s10592-009-9906-0

Dröscher I., Waringer J. 2007. Abundance and microhabitats of freshwater sponges (Spongillidae) in a Danubean floodplain in Austria. Freshwater Biology 52(6). DOI: $10.1111 /$ j.1365-2427.2007.01747.x

Duran S. et al. 2002. Polymorphic microsatellite loci in the sponge Crambe crambe (Porifera: Poecilosclerida) and their variation in two distant populations. Molecular Ecology Notes 2(4). DOI: 10.1046/j.1471-8286.2002.00285.x

DuranS., PascualM., EstoupA.etal. 2004.Strong population structure in the marine sponge Crambe crambe (Poecilosclerida) as revealed by microsatellite markers. Molecular Ecology 13(3). DOI: 10.1046/j.1365-294X.2004.2080.x

Efremova S.M. 2004. New genus and new species of sponges from family Lubomirskiidae Rezvoj, 1936. In: Timoshkin O.A. (Ed.), Opredelitel' presnovodnykh bespozvonochnykh Rossii i sopredel'nykh territoriy [Index of animal species inhabiting Lake Baikal and its catchment area]. Novosibirsk, pp. 1261-1278. (in Russian)

Fontaneto D., Barraclough T.G., Chen K. et al. 2008. Molecular evidence for broad-scale distributions in bdelloid rotifers: everything is not everywhere but most things are very widespread. Molecular Ecology 17(13). DOI: 10.1111/j.1365-294X.2008.03806.X

Fungtammasan A., Ananda G., Eile S.H. et al. 2015. Accurate typing of short tandem repeats from genome-wide sequencing data and its applications 25(5): 736-749. DOI: 10.1101/gr.185892.114

De Gelas K., De Meester L. 2005. Phylogeography of Daphnia magna in Europe. Molecular Ecology 14(3). DOI: 10.1111/j.1365-294X.2004.02434.x

Giles E.C., Saenz-Agudelo P., Berumen M.L. et al. 2013. Novel polymorphic microsatellite markers developed for a common reef sponge, Stylissa carteri. Marine Biodiversity 43(3). DOI: $10.1007 /$ s12526-013-0151-x

González-Ramos J., Agell G., Uriz M.J. 2015. Microsatellites from sponge genomes: the number necessary for detecting genetic structure in Hemimycale columella populations. Aquatic Biology 24(1). DOI: 10.3354/ab00630

Guardiola M., Frotscher J., Uriz M.J. 2012. Genetic structure and differentiation at a short-time scale of the introduced calcarean sponge Paraleucilla magna to the western Mediterranean. Hydrobiologia 687(1). DOI: $10.1007 /$ s10750-011-0948-1

Gustincich S., Manfioletti G., Del Sal G. et al. 1991. A fast method for high-quality genomic DNA extraction from whole human blood. Biotechniques 11(3): 298-300.

Hoare K., Goldson A.J., Giannasi N. et al. 2001. Molecular phylogeography of the cosmopolitan bryozoan Celleporella hyalina: cryptic speciation? Molecular Phylogenetics and Evolution 18(3). DOI: $10.1006 / \mathrm{mpev} .2000 .0892$

Hoshino S., Fujita T. 2006. Isolation of polymorphic microsatellite markers from Hymeniacidon sinapium (Porifera: Demospongiae: Halichondrida). Molecular Ecology Notes 6(3). DOI: $10.1111 / \mathrm{j} .1471-8286.2006 .01360 . \mathrm{x}$

Hoshino S., Saito D.S., Fujita T. 2008. Contrasting genetic structure of two Pacific Hymeniacidon species. Hydrobiologia 603(1). DOI: 10.1007/s10750-008-9295-2

Itskovich V., Gontcharov A., Masuda Y. et al. 2008. Ribosomal ITS sequences allow resolution of freshwater sponge phylogeny with alignments guided by secondary structure prediction. Journal of Molecular Evolution 67(6): 608-620. DOI: $10.1007 / \mathrm{s} 00239-008-9158-5$

Jaguś A., Rzętała M.A., Rzętała M. 2015. Water storage possibilities in Lake Baikal and in reservoirs impounded by the dams of the Angara River cascade. Environmental Earth Sciences 73(2): 621-628. DOI: 10.1007/s12665-014-3166-0

Kenny N.J., Francis W.R., Rivera-Vicéns R.E. et al. 2020. Tracing animal genomic evolution with the chromosomal-level assembly of the freshwater sponge Ephydatia muelleri. Nature Communications 11(1). DOI: 10.1038/s41467-020-17397-W

Knowlton A.L., Pierson B.J., Talbot S.L. et al. 2003. Isolation and characterization of microsatellite loci in the intertidal sponge Halichondria panacea. Molecular Ecology Notes 3(4). DOI: 10.1046/j.1471-8286.2003.00511.x

Kozhov M.M. 1962. Biologiya ozera Baikal [Biology of Lake Baikal]. Moscow: Akad. Nauk SSSR. (in Russian)

Li R., Nitsche F., Arndt H. 2018. Mesoscale investigations based on microsatellite analysis of the freshwater sponge Ephydatia fluviatilis in the River-Sieg system (Germany) reveal a genetic divergence. Conservation Genetics 19(2). DOI: 10.1007/s10592-018-1069-4

Lucentini L., Gigliarelli L., Puletti M.E. et al. 2013. Spatially explicit genetic structure in the freshwater sponge Ephydatia fluviatilis (Linnaeus, 1759) within the framework of the monopolisation hypothesis. Journal of Limnology 72: 172-181. DOI: 10.4081/jlimnol.2013.e14

Maldonado M., Riesgo A. 2008. Reproduction in the phylum Porifera: a synoptic overview. Treballs de la Societat Catalana de Biologia [Works of the Catalan Society of Biology] 59: 29-49. DOI: $10.2436 / 20.1501 .02 .56$

Manconi R., Pronzato R. 2008. Global diversity of sponges (Porifera: Spongillina) in freshwater. Hydrobiologia 595: 27-33. DOI: $10.1007 /$ s10750-007-9000-x

Massard J.A., Geimer G. 2008. Global diversity of bryozoans (Bryozoa or Ectoprocta) in freshwater. Hydrobiologia 595(1). DOI: $10.1007 /$ s10750-007-9007-3

Mills S., Lunt D.H., Gómez A. 2007. Global isolation by distance despite strong regional phylogeography in a small metazoan. BMC Evolutionary Biology 7(1). DOI: 10.1186/1471-2148-7-225

Muñoz J., Pacios F. 2010. Global biodiversity and geographical distribution of diapausing aquatic invertebrates: the case of the cosmopolitan brine shrimp, Artemia (Branchiopoda, Anostraca). Crustaceana 83(4). DOI: 10.1163/001121610X489449

Noyer C., Agell G., Pascual M. et al. 2009. Isolation and characterization of microsatellite loci from the endangered Mediterranean sponge Spongia agaricina (Demospongiae: Dictyoceratida). Conservation Genetics 10(6): 1895-1898. DOI: $10.1007 / \mathrm{s} 10592-009-9848-6$

Noyer C., Becerro M.A. 2012. Relationship between genetic, chemical, and bacterial diversity in the AtlantoMediterranean bath sponge Spongia lamella. Hydrobiologia 687(1). DOI: $10.1007 / \mathrm{s} 10750-011-0884-0$

Philippe H., Derelle R., Lopez P. et al. 2009. Phylogenomics revives traditional views on deep animal relationships. Current Biology 19(8): 706-712. DOI: 10.1016/j.cub.2009.02.052

Riesgo A., Pérez-Portela R., Pita L. et al. 2016. Population structure and connectivity in the Mediterranean sponge Ircinia fasciculata are affected by mass mortalities and hybridization. 
Heredity 117: 427-439. DOI: 10.1038/hdy.2016.41

Roveta C., Annibaldi A., Afghan A. et al. 2021. Biomonitoring of heavy metals: the unexplored role of marine sessile taxa. Applied Sciences (Switzerland) 11(2). DOI: $\underline{10.3390 / \text { app11020580 }}$

van Soest R.W.M., Boury-Esnault N., Vacelet J. et al. 2012. Global diversity of sponges (Porifera). PLoS ONE 7(4). DOI: 10.1371 /journal.pone.0035105

Taboada S., Kenny N.J., Riesgo A. et al. 2018. Mitochondrial genome and polymorphic microsatellite markers from the abyssal sponge Plenaster craigi Lim \& Wiklund, 2017: tools for understanding the impact of deep-sea mining. Marine Biodiversity 48(1). DOI: $\underline{10.1007 /}$ s12526-017-0786-0

Veynberg E. 2009. Fossil sponge fauna in Lake Baikal region. In: Müller W.E.G., Grachev M.A. (Eds.), Biosilica in evolution, morphogenesis, and nanobiotechnology. Progress in molecular and subcellular biology. Vol. 47. Springer: Berlin, Heidelberg, pp. 185-205. DOI: $\underline{10.1007 / 978-3-540-88552-8 \& 8}$
Vohmann A., Mutz M., Arndt H. et al. 2009. Grazing impact and phenology of the freshwater sponge Ephydatia muelleri and the bryozoans Plumatella emarginata and Fredericella sultana under experimental warming. Freshwater Biology 54(5). DOI: 10.1111/j.1365-2427.2008.02155.x

Yakhnenko A.S., Itskovich V.B. 2020a. Analysis of mtDNA variability in closely related Baikal sponge species for new barcoding marker development. Limnology 21(3). DOI: 10.1007/s10201-019-00599-7

Yakhnenko A.S., Itskovich V.B. 2020b. Study of microsatellite cross-species specificity in freshwater sponge families Lubomirskiidae and Spongillidae. Limnology and Freshwater Biology 6: 1084-1089. DOI: 10.31951/2658-3518-2020-a-6-1084

Ye J., Coulouris G., Zaretskaya I. et al. 2012. PrimerBLAST: a tool to design target-specific primers for polymerase chain reaction. BMC Bioinformatics 13 . DOI: $\underline{10.1186 / 1471-2105-13-134}$ 